OPEN ACCESS

Edited by:

Emma J. Liu,

University College London, United Kingdom

Reviewed by:

Ulrich Kueppers,

Ludwig Maximilian University of

Munich, Germany

Kieran T. Wood,

University of Bristol, United Kingdom

*Correspondence:

Ermanno Brosch

e.brosch@massey.ac.nz

Specialty section:

This article was submitted to

Volcanology,

a section of the journal

Frontiers in Earth Science

Received: 08 November 2021

Accepted: 27 January 2022

Published: 24 February 2022

Citation:

Brosch E (2022) Volcanic Ash and Small Uncrewed Aerial Vehicle (sUAV) Interaction: In-situ Observations and Laboratory Experiments on Aircraft Failure.

Front. Earth Sci. 10:810962. doi: 10.3389/feart.2022.810962

\section{Volcanic Ash and Small Uncrewed Aerial Vehicle (sUAV) Interaction: In-situ Observations and Laboratory Experiments on Aircraft Failure}

\author{
Ermanno Brosch * \\ Volcanic Risk Solutions, Massey University, Palmerston North, New Zealand
}

The deployment of small uncrewed aerial vehicles (sUAVs) for volcanological applications has grown over the last decade, mainly attributed to the development of affordable, smaller, and versatile platforms. However, the use of sUAVs in active volcanic regions is a challenging operation conducted under extreme environmental conditions. The here reported unsuccessful deployment of an SUAV at Stromboli volcano shows that the aircraft functionality was impaired by airborne volcanic ash, which led to an uncontrolled landing of the aircraft. Laboratory analyses confirmed the presence of volcanic material inside the motors, which is attributed to have caused motor blockage of the sUAV on Stromboli volcano while the aircraft was engulfed by a rising ash plume. Laboratory experiments were conducted to investigate the interaction between volcanic ash and an sUAV motor-propeller assemble. The experiments reproduced the incorporation of ashsized particles into the motor, proving that volcanic ash can enter the rotating motor while the sUAV is airborne. This shows that ash ingestion into the sUAV at Stromboli volcano resulted in operational failure. These findings shall aid in developing advanced and reliable sUAVs that can extend current deployment opportunities in volcanic environments.

Keywords: sUAV, UAV, drone, volcano, volcanic plume, volcanic ash, motor blockage, aircraft failure

\section{INTRODUCTION}

The last decade saw an exponential development and deployment of small uncrewed aerial vehicles (sUAVs) for volcanic monitoring applications (Jordan, 2019; James et al., 2020). These remotely piloted aircrafts with a total weight of less than $25 \mathrm{~kg}$ (FAA, 2016) aided in bridging the gap between satellite remote sensing and classic fieldwork (Giordan et al., 2018). The concomitant development and miniaturization of sensors resulted in the availability of adequate instrumentation for sUAVs with limited payload options (Niedzielski, 2018), increasing the application possibilities in volcanic settings.

However, any type of ground-based or aerial monitoring and data collection activity in proximity of active volcanoes is a challenging operation conducted under extreme environmental conditions. sUAVs are exposed to a wide range of environmental stress factors when deployed in volcanic areas, such as strong winds, high temperatures as well as incandescent volcanic particles, corrosive gas and vapors injected into the atmosphere. As such, sUAV malfunctions can potentially lead to a major system failure and uncontrolled landing.

Only a limited number of studies report on sUAV incidents and limitations when deployed in volcanic settings (Jordan, 2015; Jordan, 2019; James et al., 2020; Wood et al., 2020). The present study 
is one of few that reports on a sUAV incident during deployment on Stromboli volcano, Italy, in 2015. The event was triggered by the engulfment of the aircraft into an ascending erupting ash plume, which led to a malfunction and subsequent uncontrolled landing of the sUAV.

In recent years, Stromboli volcano has been subject of several successfully conducted sUAV monitoring and sampling applications (e.g. Turner et al., 2016; Turner et al., 2017; Rüdiger et al., 2018; Stix et al., 2018; Kueppers et al., 2019; Wakeford et al., 2019; Pering et al., 2020; Civico et al., 2021; Schmid et al., 2021). These missions operated the sUAVs in proximity of the active vents, hence a certain probability of failure caused by environmental conditions and volcanic activity was not to be excluded. Potential damage could as such have increased, for instance, if a sUAV was to encounter airborne volcanic ash, as the utilized aircrafts were neither dust nor waterproof.

While the destructive effects of volcanic ash on conventional propulsion aircraft engines are known (e.g. Prata and Tupper, 2009; Giehl et al., 2017), the interaction of volcanic ash with sUAVs when deployed in active volcanic regions has to date not been investigated. On the contrary, for instance, mechanical wear of moving sUAV parts due to dust and sand particles in arid ecosystems has been previously reported (Duffy et al., 2018). Industry-graded dust- and waterproof sUAV components and aircraft systems are commercially available. But, arguably, the relative low cost of prosumer and lightweight sUAVs in the market and the (from literature available) low reported incident occurrences may speak against the deployment of expensive sUAV systems, as the wealth of data collected by more affordable sUAVs possibly outweighs a potential loss of the aircraft.

This study reconstructs the events that led to the SUAV incident at Stromboli volcano and describes conducted laboratory experiments to investigate the interaction of volcanic ash with an sUAV motor-propeller assemblage. The presented results shall contribute to the development and operation of robust sUAV motor systems to lessen mission failures in future sUAV applications in proximity of active volcanic craters and vents.

\section{MATERIALS AND METHODS}

For the in-situ flight at Stromboli volcano conducted in August 2015, the selected sUAV was a modified Q500+ quadcopter (Figure 3A), a multirotor aircraft of the drone manufacturer Yuneec with a total take-off weight of c. $2.5 \mathrm{~kg}$. The sUAV was equipped with a three-axes gimbal-stabilized $4 \mathrm{~K}$ camera and a 25 min flight time 5,400 mAh Lithium polymere (LiPo) battery. In previous test flights elsewhere, flying distances (here not intended as distance from the ground station) ranged between 5 and $8 \mathrm{~km}$. Long-distance communication to the sUAV was possible by using the $\mathrm{ST} 10+$ ground station $(5.8 \mathrm{GHz}$ remote controller with customized antennas) where telemetric data and flightpath information were displayed onscreen.

To investigate the interaction of a sUAV exposed to suspended volcanic ash a series of laboratory experiments were carried out, using a sUAV motor-propeller assemblage inside an experimental chamber. The experimental system is a prototype

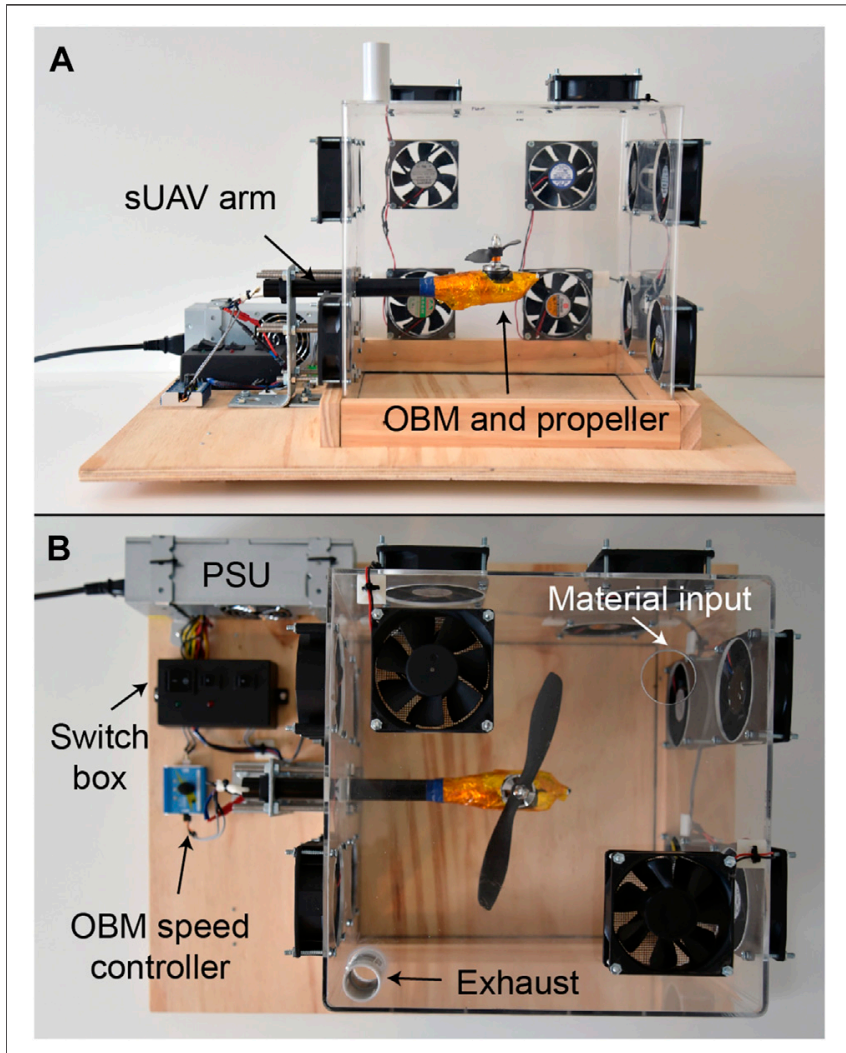

FIGURE 1 | Experimental setup used to investigate the interaction between a sUAV motor-propeller assemblage and volcanic ash. (A) Frontal view showing the sUAV arm positioned at the center of the plexiglass cube. (B) Top view showing the control section (switch box and OBM speed controller) as well as both the material input opening and air exhaust. Note that the funnel and tube to convey the material into the cube are not shown here.

designed and built by the author. The main structure is a $0.3 \times 0.3 \times$ $0.3 \mathrm{~m}$ sized clear plexiglass cube with $3.5 \mathrm{~mm}$ thick walls (Figure 1A). A sUAV arm centered at the inside of the cube is installed from one side and is held in place by two L-shaped profiles. The sUAV arm is equipped with a GAUI OBM outrunner brushless motor (Model GUEC GM-412S $960 \mathrm{KV}$ ), an ESC electronic speed controller (Model GUEC GE-183), and a $0.2 \mathrm{~m}$ diameter propeller. The OBM-ESC assemblage is powered and controlled by a conventional CCPM multi servo speed consistency controller. The rounds per minutes (rpm) of the motor are set at a constant 5,000 rpm, a value typical for sUAVs while hovering (Deters et al., 2017).

The cube is additionally fitted with 14 fans (c. $0.08 \mathrm{~m}$ fan diameter), disassembled from computer power supply units (PSUs). These are installed to increase the airflow inside the cube. The experimental system is powered by a PSU (Figure 1B). Yellow $12 \mathrm{~V}$, red $5 \mathrm{~V}$, and black ground cables as well as the green PSU powering cable are wired into a three-switch box. $12 \mathrm{~V}$ are used to power the fans and the ESC while $5 \mathrm{~V}$ are used to power the CCPM speed controller. In Figure 1B, from left to right, switch 1 turns the PSU on, switch 2 the fans, and switch 3 powers the ESC-OBM and CCPM speed controller. Two cameras at FullHD resolution $(1920 \times 1,080$ pixel $)$ and 60 frames per seconds are 
used to record the evolution of the experiment from the front and top views for describing the interaction between volcanic ash and the motor-propeller assemblage.

The volcanic material is conveyed into the chamber from the top through a funnel connected to a c. $0.2 \mathrm{~m}$ long PVC pipe (Figure 1B; only material input location visible). The bottom side of the funnel is then manually opened by quickly pulling out a thin and robust plastic sheet which is slightly narrower than the width of the connecting funnel bottom and the PVC pipe. To ensure structural stability between the funnel and the PVC pipe, most of the circumference connection between these two elements was fused together, leaving only a part unsealed to have a slot to insert and pull-out the plastic barrier. Upon opening of the barrier, the volcanic ash flows into the PVC pipe and subsequently into the experimental chamber. A small pressure exhaust pipe is fitted with a foam to avoid ash dispersal (Figure 1B; foam not installed).

Three experiments were conducted in August 2021 and for each run c. $350 \mathrm{~g}$ of volcanic material were used. The mixture was discharged over approximately $9.5 \mathrm{~s}$ into the experimental chamber. Over this discharge duration, the density inside the chamber was calculated to be c. $1.32 \mathrm{~kg} / \mathrm{m}^{3}$, based on the volume of the cube, the approximate mass of air inside it and the discharged volcanic material as a function of time. The density was not controlled over the course of the discharge time and experiment duration, but served as a guidance density only which translates into densities in the range typical for low concentration ash plumes (Patrick, 2007; Tournigand et al., 2017).

The volcanic material used for these experiments was erupted at vents within the Ohakune volcanic complex in New Zealand (Houghton and Hackett, 1984; Kósik et al., 2016). The material was sampled from the ash units of a large basaltic scoria cone complex comprising beds ranging in size from ash to bomb (Kósik et al., 2016). The material was then sieved to a grainsize $<0.5 \mathrm{~mm}$ and dried in an oven to remove any moisture.

At this initial stage, the conducted preliminary experiments were not designed to replicate the incident occurred at Stromboli volcano. Rather, they served as test experiments to investigate the physical interaction of volcanic ash and motors used in sUAV systems, regardless the potential additional damaging effects that heated ash particles may have on the integrity and operation of the aircraft. Therefore, this current experimental setup has a number of system and scaling factors limitations, which will be resolved for future studies: 1) the volcanic material is not heated, hence additional damaging processes (for instance, impacting and melting of particles into the propeller) cannot occur; 2) only particles of a limited grain size range are able to be kept in suspension ( $<250$ micron) because of limited coupling of particles to the fluid phase owing to lower turbulence intensity; 3 ) the system is currently not designed for prolonged ( $>1 \mathrm{~min}$ ) discharge rates; 4) the computed density inside of the experimental chamber is a guidance number only and cannot be accurately verified or controlled, as no analytical instruments are installed to measure it; and 5), the reduced size of the experimental chamber permits to use a single motor-propeller assemblage, rather than a complete sUAV system. Further studies are planned based on an updated version and results of this first preliminary experimental series to increase the similitude of reproduced phenomena to processes occurring in real-world situations. This will be achieved by controlling the environment inside an experimental chamber to relate external conditions to the type of damage inflicted.

\section{RESULTS}

\section{sUAV Malfunction at Stromboli Volcano}

Stromboli is an active volcanic island (summit at 924 m.a.s.l.) and is part of the Aeolian archipelago in Italy. In August 2015, a preliminary survey was planned at Stromboli volcano. The aim was primarily to test the feasibility of deploying sUAVs during volcanic activity, and secondary, to obtain high-resolution imagery of the summit craters located at c. 750 m.a.s.l. The take-off location was situated at c. 400 m.a.sl. on the northern flank of Stromboli volcano (Figure 2, yellow cross), on one of the two ridges which bound the Sciara del fuoco. The weather conditions were excellent, which allowed for additional spotting and tracking of the sUAV during its flight using a long-range binocular. The flight was conducted in the early afternoon. During the flight (yellow flightpath, Figure 2), the sUAV was hovering at around 850 m.a.s.l, c. $100 \mathrm{~m}$ above the summit craters. An unexpected stronger explosion found the sUAV in the vertical ascent path of the turbulent and incandescent ash plume. The sUAV was eventually completely engulfed by the outer regions of the rising plume. The sUAV consequently commenced to fly erratically and drifted away from the summit region downslope the Sciara del fuoco towards the open sea for c. $500 \mathrm{~m}$ (red dashed flightpath, Figure 2). After approximately a minute of irresponsiveness to commands by the ground station, the successful activation of the return to home procedure set the sUAV on a return flight (red flightpath, Figure 2). During the approach by the sUAV back to the take-off location, visual observations using a binocular indicated that one motor appeared to be completely blocked. Eventually, the sUAV became completely irresponsive at c. $100 \mathrm{~m}$ above the ground and crashed downslope from the take-off location (Figure 2), upon where signal to the ground station was lost entirely. Contact was lost for over two hours as the recovery of the $\mathrm{SUAV}$ proved to be difficult, due to the complex terrain. Considerable effort was put into the recovery of the aircraft to understand the reasons which led to this unique sUAV system failure and irresponsiveness. Eventually, recovery operations from land stopped and the sUAV was recovered with a boat ride to the shore most proximal to the estimated impact location. (Figure 2, red cross shows the recovery location of the sUAV). The ground on which the aircraft was found ranged from lapilli to block-sized (up to several decimeters) loose volcanic material. During recovery, the following observations were made on the overall integrity of the sUAV:

- The frame of the sUAV was almost completely intact, except for a number of structural failures between the arms that held the motors and the main frame on the left-hand side of 


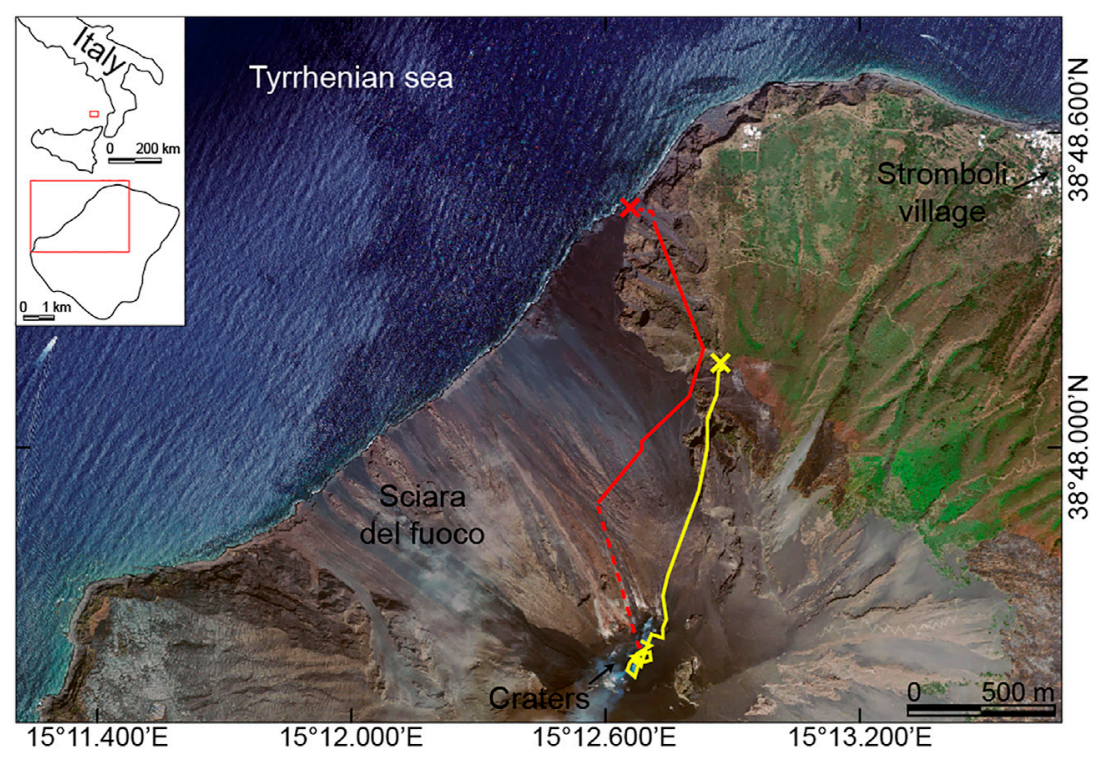

FIGURE 2 | Sentinel-2 satellite image of the north-western section of Stromboli volcano, showing the flank collapse area and the summit crater regions. Yellow cross and lines depict the take-off location and flight path, respectively. Red lines (dashed and non) show the flightpath of the sUAV while being irresponsive and partially responsive, respectively. Red cross marks the location the SUAV was recovered from.

the aircraft. No torn electric wires or connections were found.

- Three out of four propellers were destroyed.

- The impact expelled the battery pack from the sUAV body, and the pack was found a few meters away from the aircraft. Minor corrosion of the exposed battery terminals was visible.

- The $4 \mathrm{k}$ camera was damaged beyond recovery. The camera housing was broken, exposing both the control board (showing broken electric contacts and components) and the antenna for real-time video transmission.

- All four outrunner brushless motors (OBMs) presented different degrees of blockage caused by the presence of volcanic particles inside the structure (Figures 3B,C), with one motor being completely blocked and a second one barely rotating. Both were located on the left-hand side of the sUAV.

Subsequently, the motors were taken apart and the trapped volcanic material was separately collected. The particles were up to a few millimeters in size and consisted of scoriaceous clasts, denser glass fragments and crystals (Figure 3D) and the proportion of sub-millimetric particles made up c. $70 \%$ of the collected material. Of high interest was the identification of magnetic minerals such as titanomagnetites in the crystal fraction of the retrieved material, which partially exhibit a well-developed characteristic crystal shape (Figure 3E).

\section{sUAV Motor and Volcanic Ash Interaction Experiment}

The volcanic material was discharged into the experimental chamber, with the sUAV propeller and side fans fully operational. Upon entrance, coarser ash particles $(>250$ microns) partially directly sedimented straight to the base of the cube (Figures $4 \mathbf{A}, \mathbf{B})$, while the finer ash portion $(<250$ microns) remained suspended by the turbulent air flow. Between c. 3-5 s after discharge initiation, the fine ash content in suspension reached visually a maximum concentration (Figure 4C). The turbulent air flow generated inside the experimental chamber was controlled by the propeller and the side fans. Particles small enough to stay in suspension were thus coupled to the turbulent air flow. The turbulent ash-air mixture moved from top to bottom inside the chamber, concentrating around the motor-propeller assemblage, thus creating a zone of higher particle concentration. This permitted the ingestion of the volcanic particles into the inside of the motor. Visibly also was a vortex-like shape of the deposited material at the base of the cube due to the rotational turbulent motion of the air directly underneath the propeller (Figure 4C). At c. $8 \mathrm{~s}$ the plexiglass walls started to be covered in ash (Figure 4D). Subsequently, after c. $9.5 \mathrm{~s}$ the material discharge stopped, and the experiment was concluded approximately 12-14 s after discharge initiation.

In all three cases, the motor did not block, and appeared instead to be fully operational throughout the conduction of the experiments. However, while disassembling the sUAV arm from the setup, a faint grinding noise was audible while manually rotating the motor and propeller. The motor was carefully disassembled, and the loose material was collected. A close-up inspection under an optical microscope revealed the presence of particles stuck on the coils of the stator part of the motor (Figure 4E). Similarly, observations of the rotor part of the motor showed that most of the trapped volcanic material concentrated around its upper part, close to the ventilation gaps, thus at the upper end of the magnets (Figure 4F; rotor 


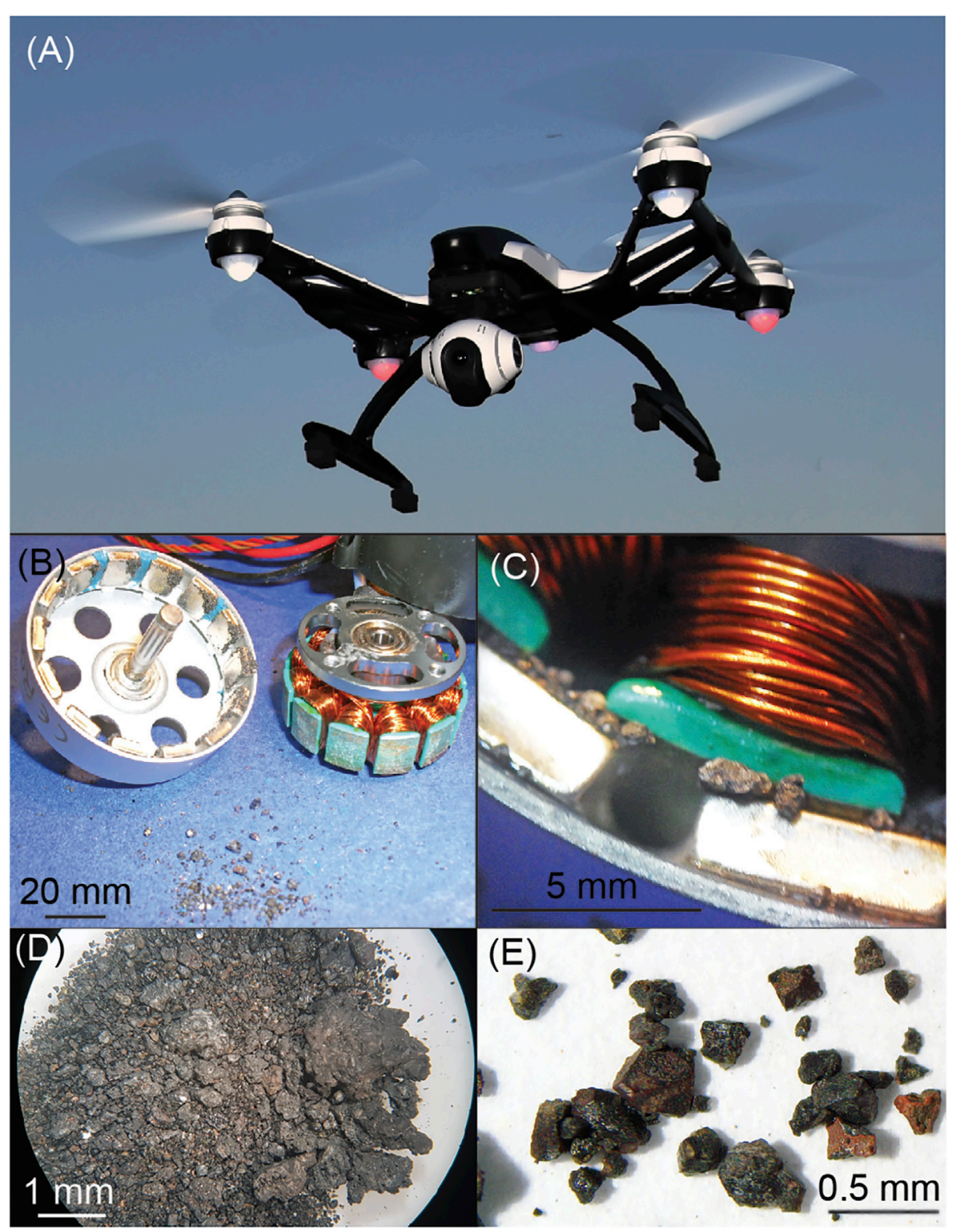

FIGURE 3 | (A) The sUAV deployed on Stromboli volcano featuring the 4K camera on its bottom side. (B) The disassembled motor showing the trapped volcanic material. (C) Close-up of the material trapped inside the motor between the magnets of the rotor and the coils of the stator. (D) Microscopy image of the volcanic material retrieved from one motor. Grain sizes vary from sub-millimetric up to a few millimeters. (E) Close-up magnification of titanomagnetite crystals, which constitute part of the trapped volcanic material inside the motors.

is pictured upside down). The trapped volcanic material was finer-grained than the overall grain-size range of the experimental mixture but contained the same type of components, namely scoriaceous clasts, denser glass fragments and crystals (Figure 4G). The material was thus sieved to determine the trapped grain-size fraction. All trapped particles were smaller than approximately 250 microns. Similarly, as with the incident at Stromboli volcano, magnetic particles were trapped inside the motor (Figure 4H; example of trapped magnetic particle). A closer inspection was not possible because of limitations in the resolution of the optical microscope, but these magnetic particles were part of the experimental volcanic material, and not metallic fragments of the motor structure.

\section{DISCUSSION}

\section{sUAV Malfunction and Crash on Stromboli Volcano}

While the SUAV was engulfed by the turbulent rising ash cloud, at least one motor was temporarily blocked because of overheating of one of the electronic speed controllers (ESC). The ESCs were 

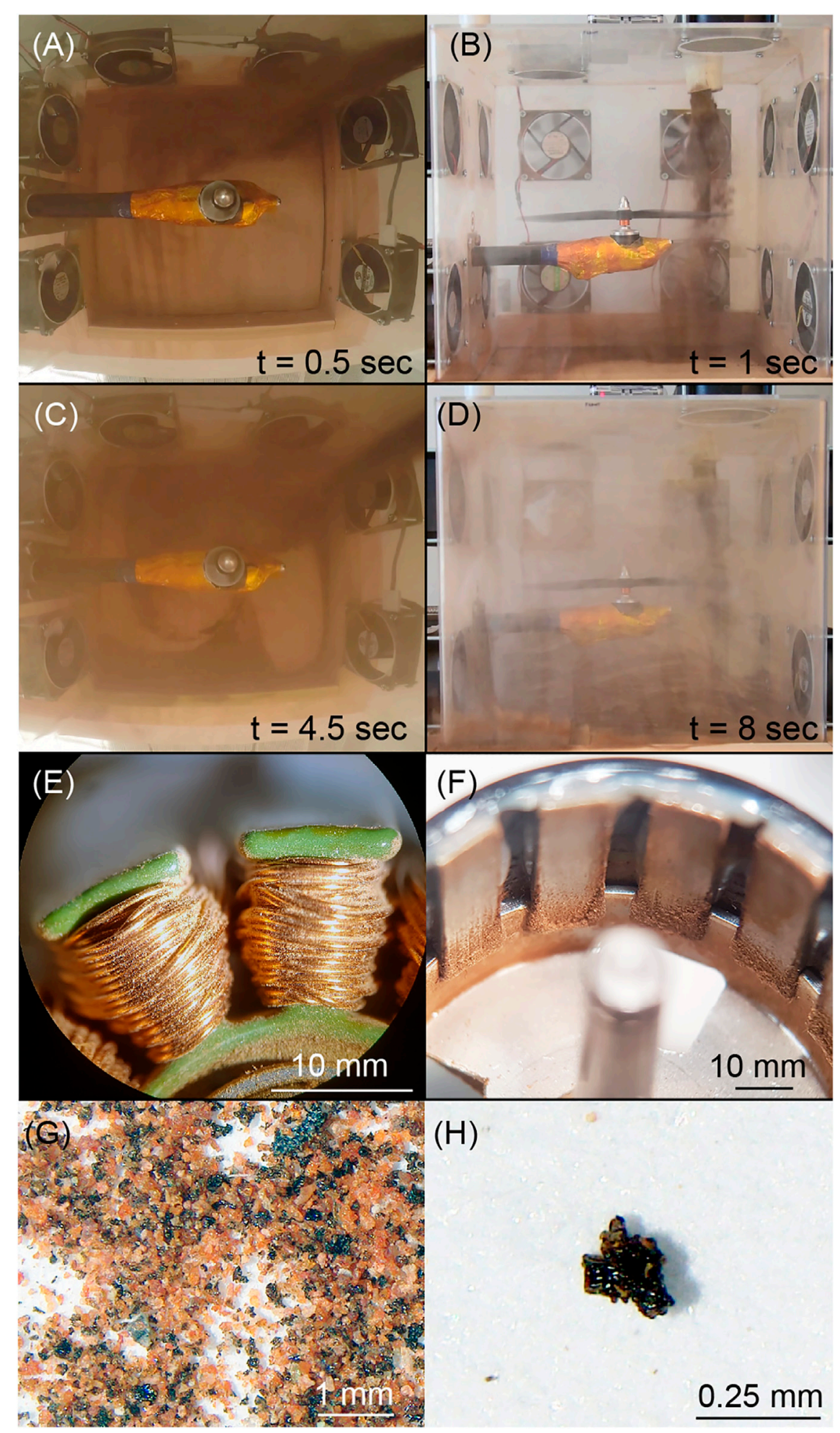

FIGURE 4 | Preliminary experimental results of ash-motor interactions. (A-D) Snapshots at four different times showing the ash entering the plexiglass cube and being incorporated into the turbulent airflow, generated by the rotating propeller and fans located at the sides of the cube. (E) Close-up image of the stator coils of the disassembled motor with a visible fine-ash layer deposited onto the wires. (F) Microscopy image of deposited volcanic material on the rotor magnets. (G) Collected volcanic material trapped inside the motor (<500 micron), showing several components (scoriaceous clasts, denser glass fragments and crystals). (H) Close-up view of a magnetic particle in the volcanic material sampled from the motor's inside. 
requiring considerable current from the battery to stabilize the sUAV in a hovering position due to winds that were present in the summit region of Stromboli. When the sUAV was engulfed by the ash cloud, small particles started to enter inside the motor, which led to a material build up and an increase in internal friction. To counteract the loss of motor rotations, more current was required by the ESCs to ensure the aircraft stayed in position. This led to overheating of the ESC and failure to control the motor. The motor momentarily ceased to rotate and blocked because of increased ash incorporation. While ESC overheating issues are not common as the airflow around the frame of a sUAV is sufficient to cool ESCs, these can occur especially when sUAV systems are exposed to excessive external stress or when electronic components are defective (in the case of ESCs, typically capacitors or transistors) (Shin and Teh, 2018). At the same time, the control software of the sUAV most likely induced a return-to-home procedure caused by the battery approaching a low level of charge. One motor appeared to be blocked but this was difficult to confirm, even after the operator managed to momentarily regain control of the aircraft and maneuvered the sUAV towards the take-off location. The sUAV was able to continue flying down the slope of Stromboli volcano due to a combination of unique external factors, such as ascending winds upwards the flank of the volcano which aided the light-weight aircraft to stay airborne [as similarly described by James et al. (2020)]. Concomitantly, while the sUAV was drifting away from the summit region, the blocked motor must have become, at least partially, operational again but largely impaired in its functionality. The sUAV did not lose altitude during the engulfment of the ash plume because of the buoyant nature of the rising ash plume, which lifted the sUAV. A similar process has been reported by Wood et al. (2020) where a deployed fixed-wing sUAV experienced a fast vertical acceleration by expelled buoyant gas from a volcanic vent.

The automatic positioning system of the sUAV failed to ensure a stable flight path while drifting away from the crater region because of 1) high current drainage by the ESC and motor to counterbalance the impaired functionality, and 2) strong upward thrust generated by ascensional winds. These processes led to irregular round per minute rotations of the four motors, thus greatly destabilizing the aircraft beyond the control of the automatic positioning system which therefore was unable to counterbalance the abnormal flying condition.

Furthermore, build-up of electrostatic charge in the rising ash plume and the surrounding atmosphere in proximity of the vents (e.g. James et al., 2008; Pähtz et al., 2010) may have further influenced the electronics of the sUAV causing additional communication and operation problems.

The exact impact location of the sUAV is not known but must have been not too distant from the recovery location of the sUAV (Figure 2, red cross). Remarkably, the main body and the landing gear of the sUAV did not sustain extensive damage. However, the structural damage on the body indicated that it impacted with its left side on the ground. This was confirmed by the two propellers on the left-hand side which were completely broken, compared to the propellers on the opposite side which were only partially damaged. The camera/gimbal structure showed major signs of damage inflicted by the impact and dragging on the ground.

Furthermore, during the two-hour time frame between aircraft crash and recovery, corrosion of both the battery pack terminals and the coils of the stator inside the motor occurred. The reasons are two-fold and can be attributed to the corrosive nature of gas and vapor emissions by the plume (e.g. Symonds et al., 2018) when the sUAV was engulfed causing damage to structure and electronics (e.g. Gordon et al., 2005), and the presence of sea spray close to the shore which caused fast corrosion of metallic parts.

\section{Ash Incorporation in the sUAV Motors and Blockage}

At Stromboli volcano, the ingestion of ash into the motors occurred while the sUAV was airborne and additionally when it impacted on the ground. Upon impact, the battery pack was expelled from the aircraft and found a few meters apart from the sUAV. The subsequent slowing down of the propellers therefore aided in incorporating particles into the motors. This occurred because the cooling fissures on the stator part of the motors allowed for increased entrance of particles due to no rotation. Therefore, it is here concluded that the coarser particle fraction (Figures 3C,D. $1 \mathrm{~mm}$ up to a few millimeter-sized particles) found inside the motors of the sUAV entered precisely during the impact of the aircraft on the ground covered with unconsolidated volcanic material. In contrast to this, a large quantity of the smaller particle fraction of the collected volcanic ash (here concluded to be $<500$ microns) entered when the sUAV was engulfed by the ascending ash cloud in the summit region of Stromboli. Considering that the rotation of the stator leaves the cooling fissures less exposed, it is here concluded that only smaller particles were ingested. Possibly, a smaller amount entered during the impact, but the substrate the sUAV impacted onto was composed of lapilli-to block-sized volcanic material.

The incorporation of different grain-size fractions while airborne and during impact on the ground is in line with the results obtained from the preliminary laboratory experiments. The motor inside the experimental chamber ingested particles of a smaller grain size ( $<250$ microns) compared to the coarser particles (up to 500 microns), which sedimented to the base. This could indicate that when sUAVs are either in the proximity of or are engulfed by volcanic plumes, motors only incorporate a specific grain-size fraction into their internal mechanical structure. However, a comparison with the experimental outcomes should be interpreted with caution, since a stronger turbulent air flow in the experimental chamber might have aided in suspending the entire experimental volcanic mixture, hence including particles coarser than 250 microns up to 500 microns. However, the observations of the incident on Stromboli volcano suggest that the coarser grain-size fraction of the collected material trapped inside the motor was ingested during the impact of the sUAV on the unconsolidated ground.

In both the Stromboli scenario and the experimental series, volcanic particles entered inside the sUAV motors through superficial cooling structures. The strong turbulent airflow can therefore continuously and increasingly convey particles into the 
motor, thus potentially speeding up blockage. Furthermore, magnetic particles are especially attracted to and adhere on magnets located on the stator. This leads to particle build-up and friction which further impairs the rotation. It should be also considered that such particles are less likely to be forced out of the interior of a motor while operational.

To conclude this analysis, several reasons speak for the diverging experimental result of non-blockage of the sUAV motor compared to the motor blockage events on Stromboli volcano. This has been anticipated in the methods section presenting several limitations which impacted the experimental outcome. The three most decisive reasons are the size of the experimental chamber and the limited degree of turbulence generated inside, next to the inability to perform tests on a complete sUAV system. Nevertheless, while motor blockage was experimentally not achieved, the experiments reproduced the ingestion of ash in a sUAV motor. This aided in understanding the events and processes that led to the failure of the sUAV vehicle deployed on Stromboli volcano.

\section{CONCLUSION}

This study presents a detailed reconstruction of the events that led to the malfunction of a sUAV deployed on Stromboli volcano. The sUAV was engulfed by a rising eruption plume and the ingestion of volcanic particles into the motors led to an uncontrolled flight and loss of control, followed by a crash on unconsolidated ground. Laboratory experiments have been conducted to replicate the scenario and to investigate the interaction of volcanic ash with a motor-propeller assemblage. The experimental series successfully reproduced the incorporation of ash inside the sUAV motor, however failed at reproducing a blockage of the motor. While the latter was not the primary aim of the experiments, these show that even at much smaller scales, compared to real-world scenarios, fine-grained volcanic particles are ingested by the motors. Translated onto a real-world volcanic eruption scenario such as the incident on Stromboli volcano, where environmental conditions, energy scales and the amount of suspended volcanic ash capable of entering inside a motor are larger by orders of magnitudes, these processes can lead to complete system destructions. This study shows that sUAV motors are susceptible to being either impaired in their functionality or completely blocked by airborne volcanic particles.

Experimentally, no blockage occurred due to only fine ash ( $<250$ micron) captured inside the motor, but the presence of magnetic particles inside the motor suggests that blockage can occur faster if the concentration of these particles is sufficiently high. Related to the presented observations from Stromboli volcano, the discovery of magnetic minerals inside the

\section{REFERENCES}

Civico, R., Ricci, T., Scarlato, P., Andronico, D., Cantarero, M., Carr, B. B., et al. (2021). Unoccupied Aircraft Systems (UASs) Reveal the Morphological motors of the crashed sUAV suggests that these particles were critical in aggravating the blockage, as these are less likely to be expelled.

Further experiments (currently in the planning phase) are necessary to better constrain which grain-sizes and, possibly, which volcanic particle types are preferentially ingested by sUAV motors. Furthermore, the amount of ingested magnetic and nonmagnetic volcanic particles may decrease inside a sUAV motor because of centrifugal force generated by the motor, providing the sUAV flies away from a volcanic plume or surrounding airborne particle concentration decreases. However, this requires further investigation. Additionally, it will be of interest to quantify the critical mass of the ingested ash necessary to cause motor blockage. Therefore, having the ability of controlling the boundary conditions (e.g., turbulence intensity, temperature, and grain-size distribution of the volcanic ash-air mixture) inside an experimental chamber and the option of conducting tests on an entire sUAV system will allow to better constrain the damage afflicted to the aircraft.

\section{DATA AVAILABILITY STATEMENT}

The original contributions presented in the study are included in the article/Supplementary Material, further inquiries can be directed to the corresponding author.

\section{AUTHOR CONTRIBUTIONS}

EB confirms sole responsibility for study design, field work, data collection, experiment design and construction, data analyses, interpretation of results, and manuscript preparation.

\section{FUNDING}

This work was supported by Resilience to Nature's Challenges Volcano Theme (GNS-RNC047) and VFF Mare Nostrum eV Austria travel grant.

\section{ACKNOWLEDGMENTS}

Marco Mora (A.R.A.S) is thanked for technical assistance on Stromboli. Andrea Todde is thanked for assistance during the material collection. Stefania Romero-Ramirez is thanked for technical assistance during preparation and conduction of the experiments. Ulrich Küppers and Kieran T. Wood are thanked for their valuable suggestions which greatly improved the manuscript. Emma Liu is thanked for editorial handling.

Changes at Stromboli Volcano (Italy) before, between, and after the 3 July and 28 August 2019 Paroxysmal Eruptions. Remote Sensing 13 (15), 2870. doi:10.3390/rs13152870

Deters, R. W., Kleinke, S., and Selig, M. S. (2017). "Static Testing of Propulsion Elements for Small Multirotor Unmanned Aerial Vehicles," in Proceeding of 
the 35th AIAA Applied Aerodynamics Conference, Denver, Colorado, June 2017.

Duffy, J. P., Cunliffe, A. M., DeBell, L., Sandbrook, C., Wich, S. A., Shutler, J. D., et al. (2018). Location, Location, Location: Considerations when Using Lightweight Drones in Challenging Environments. Remote Sens Ecol. Conserv 4 (1), 7-19. doi:10.1002/rse2.58

FAA (2016). "Small Unmanned Aircraft Systems (sUAS)," in AC 107-2. Editor F. A. Administration (Washington DC: U.S. Department of Transportation).

Giehl, C., Brooker, R. A., Marxer, H., and Nowak, M. (2017). An Experimental Simulation of Volcanic Ash Deposition in Gas Turbines and Implications for Jet Engine Safety. Chem. Geology. 461, 160-170. doi:10.1016/j.chemgeo.2016.11.024

Giordan, D., Hayakawa, Y., Nex, F., Remondino, F., and Tarolli, P. (2018). Review Article: the Use of Remotely Piloted Aircraft Systems (RPASs) for Natural Hazards Monitoring and Management. Nat. Hazards Earth Syst. Sci. 18 (4), 1079-1096. doi:10.5194/nhess-18-1079-2018

Gordon, K. D., Cole, J. W., Rosenberg, M. D., and Johnston, D. M. (2005). Effects of Volcanic Ash on Computers and Electronic Equipment. Nat. Hazards 34 (2), 231-262. doi:10.1007/s11069-004-1514-1

Houghton, B. F., and Hackett, W. R. (1984). Strombolian and phreatomagmatic deposits of Ohakune craters, Ruapehu, New Zealand: A complex interaction between external water and rising basaltic magma. J. Volcanol. Geother. Res. 21 (3), 207-231.

James, M. R., Wilson, L., Lane, S. J., Gilbert, J. S., Mather, T. A., Harrison, R. G., et al. (2008). Electrical Charging of Volcanic Plumes. Space Sci. Rev. 137 (1), 399-418. doi:10.1007/978-0-387-87664-1_25

James, M., Carr, B., D’Arcy, F., Diefenbach, A., Dietterich, H., Fornaciai, A., et al. (2020). Volcanological Applications of Unoccupied Aircraft Systems (UAS): Developments, Strategies, and Future Challenges. Volcanica 3 (1), 67-114. doi:10.30909/vol.03.01.67114

Jordan, B. R. (2015). A Bird's-Eye View of Geology: The Use of Micro drones/ UAVs in Geologic Fieldwork and Education. Gsat 25 (7), 50-52. doi:10.1130/ gsatg232gw.1

Jordan, B. R. (2019). Collecting Field Data in Volcanic Landscapes Using Small UAS (sUAS)/drones. J. Volcanology Geothermal Res. 385, 231-241. doi:10.1016/ j.jvolgeores.2019.07.006

Kósik, S., Németh, K., Kereszturi, G., Procter, J. N., Zellmer, G. F., and Geshi, N. (2016). Phreatomagmatic and Water-Influenced Strombolian Eruptions of a Small-Volume Parasitic Cone Complex on the Southern Ringplain of Mt. Ruapehu, New Zealand: Facies Architecture and Eruption Mechanisms of the Ohakune Volcanic Complex Controlled by an Unstable Fissure Eruption. J. Volcanology Geothermal Res. 327, 99-115. doi:10.1016/j.jvolgeores. 2016.07.005

Kueppers, U., Huber, J., Schmid, M., Walker, B. H., Andronico, D., Johnson, J. B., et al. (2019). Drone-deployed Sensors Capture Multi-Parameter Perspective of Explosions at Stromboli Volcano. Vienna: Geophysical Research Abstracts.

Niedzielski, T. (2018). Applications of Unmanned Aerial Vehicles in Geosciences: Introduction. Pure Appl. Geophys. 175 (9), 3141-3144. doi:10.1007/s00024018-1992-9

Pähtz, T., Herrmann, H. J., and Shinbrot, T. (2010). Why Do Particle Clouds Generate Electric Charges? Nat. Phys. 6 (5), 364-368. doi:10.1038/nphys1631

Patrick, M. R. (2007). Dynamics of Strombolian Ash Plumes from thermal Video: Motion, Morphology, and Air Entrainment. J. Geophys. Res. Solid Earth 112 (B6), B06202. doi:10.1029/2006jb004387

Pering, T. D., Liu, E. J., Wood, K., Wilkes, T. C., Aiuppa, A., Tamburello, G., et al. (2020). Combined Ground and Aerial Measurements Resolve Vent-specific Gas Fluxes from a Multi-Vent Volcano. Nat. Commun. 11 (1), 3039. doi:10.1038/ s41467-020-16862-w
Prata, A. J., and Tupper, A. (2009). Aviation Hazards from Volcanoes: the State of the Science. Nat. Hazards 51 (2), 239-244. doi:10.1007/s11069-009-9415-y

Rüdiger, J., Tirpitz, J. L., de Moor, J. M., Bobrowski, N., Gutmann, A., Liuzzo, M., et al. (2018). Implementation of Electrochemical, Optical and Denuder-Based Sensors and Sampling Techniques on UAV for Volcanic Gas Measurements: Examples from Masaya, Turrialba and Stromboli Volcanoes. Atmos. Meas. Tech. 11 (4), 2441-2457. doi:10.5194/amt-11-2441-2018

Schmid, M., Kueppers, U., Civico, R., Ricci, T., Taddeucci, J., and Dingwell, D. B. (2021). Characterising Vent and Crater Shape Changes at Stromboli: Implications for Risk Areas. Volcanica 4 (1), 87-105. doi:10.30909/vol.04.01. 87105

Shin, Y. T., and Teh, Y. (2018). "Design Analysis and Considerations of Power Efficient Electronic Speed Controller for Small-Scale Quadcopter Unmanned Aerial Vehicle," in Proceeding of the 2018 IEEE 8th Annual Computing and Communication Workshop and Conference (CCWC), Las Vegas, NV, USA, Jan. 2018 (IEEE), 773-776.

Stix, J., D’Arcy, F., Grassa, F., Aiuppa, A., and Rizzo, A. L. (2018). Near Real-Time Isotopic Measurements of $\mathrm{CO} 2$ Sampled by Drone at Stromboli, Italy. Washington DC: AGU Fall Meeting, V23D-V0110.

Symonds, R. B., Rose, W. I., Bluth, G. J. S., and Gerlach, T. M. (2018). "Chapter 1. Volcanic-Gas Studies: Methods, Results, and Applications," in Volatiles in Magmas. Editors R. C. Michael and R. H. John (Washington DC: De Gruyter), 1-66.

Tournigand, P.-Y., Taddeucci, J., Gaudin, D., Peña Fernández, J. J., Del Bello, E., Scarlato, P., et al. (2017). The Initial Development of Transient Volcanic Plumes as a Function of Source Conditions. J. Geophys. Res. Solid Earth 122 (12), 9784-9803. doi:10.1002/2017jb014907

Turner, N., Houghton, B. F., von der Lieth, J., Hort, M., Taddeucci, J., Kueppers, U., et al. (2016). Mapping the Active Vents of Stromboli Volcano with an Unmanned Aerial Vehicle. San Francisco: AGU Fall Meeting, V43A-V3125.

Turner, N., Taddeucci, J., Houghton, B., von der Lieth, J., Kueppers, U., Gaudin, D., et al. (2017). Drone Peers into Open Volcanic Vents. Eos 98, eo082751. doi:10. 1029/2017eo082751

Wakeford, Z. E., Chmielewska, M., Hole, M. J., Howell, J. A., and Jerram, D. A. (2019). Combining thermal Imaging with Photogrammetry of an Active Volcano Using UAV: an Example from Stromboli, Italy. Photogram Rec. 34 (168), 445-466. doi:10.1111/phor.12301

Wood, K., Liu, E. J., Richardson, T., Clarke, R., Freer, J., Aiuppa, A., et al. (2020). BVLOS UAS Operations in Highly-Turbulent Volcanic Plumes. Front. Robotics AI 7 (136). doi:10.3389/frobt.2020.549716

Conflict of Interest: The authors declare that the research was conducted in the absence of any commercial or financial relationships that could be construed as a potential conflict of interest.

Publisher's Note: All claims expressed in this article are solely those of the authors and do not necessarily represent those of their affiliated organizations, or those of the publisher, the editors and the reviewers. Any product that may be evaluated in this article, or claim that may be made by its manufacturer, is not guaranteed or endorsed by the publisher.

Copyright $\odot 2022$ Brosch. This is an open-access article distributed under the terms of the Creative Commons Attribution License (CC BY). The use, distribution or reproduction in other forums is permitted, provided the original author(s) and the copyright owner(s) are credited and that the original publication in this journal is cited, in accordance with accepted academic practice. No use, distribution or reproduction is permitted which does not comply with these terms. 